\title{
New ways to deal with Omni-channel services: Opening the door to synergies, or problems in the horizon?
}

\author{
João Reis \\ Department of Economics, Management and Industrial Engineering and Tourism, Aveiro \\ University, Aveiro, Portugal \\ reis.joao@ua.pt \\ Marlene Amorim \\ Department of Economics, Management and Industrial Engineering and Tourism, \\ and GOVCOPP, Aveiro University, Portugal \\ mamorimeua.pt \\ Nuno Melão \\ Department of Management and CI\&DETS, School of Technology and Management \\ of Viseu, Polytechnic Institute of Viseu, Viseu, Portugal \\ nmelaodestgv.ipv.pt
}

\begin{abstract}
This article aims to investigate organizational synergies in the omnichannel service context. In doing so, it discloses new omni-channel trends and discusses its implications for managers and academics. It uses a qualitative multimethod approach, which includes more than one method of collecting data to generate comprehensiveness and rich knowledge, namely: a systematic literature review and a case study. The transition to an omni-channel service requires companies to overcome many organizational challenges and is compelling academics and practitioners to focus on its operations management. The results indicate that organizational synergies are changing the omni-channel landscape and may provide several opportunities for gaining competitive advantages by implementing new technologies (e.g. m-payments), and anticipating customer needs (e.g. multi-brand experience). It is possible that these organizational synergies are transcending the omni-channel concept, creating new trends, but to confirm this hypothesis further investigation is needed.
\end{abstract}

Keywords: Organizational synergies, Omni-channel services, Qualitative multimethod approach, Systematic literature review, Case study, Competitive advantage, Operations management.

\section{Introduction}

Recent times have seen an increasing interest in omni-channel services. Whereas traditional retail players are ramping up their Internet presence, online-first retailers are complementing their service delivery systems by opening stores and showrooms [1]. Customers are becoming more self-assured in employing electronic devices (e.g. laptops, tablets, mobile phones...) both for product search and order placement [2]. Moreover, the service delivery arena is now evolving from the adoption of multichannel approaches, where customers are offered alternative channels, towards the pursuit of omni-channel strategies that aim at leveraging on integration, and the 